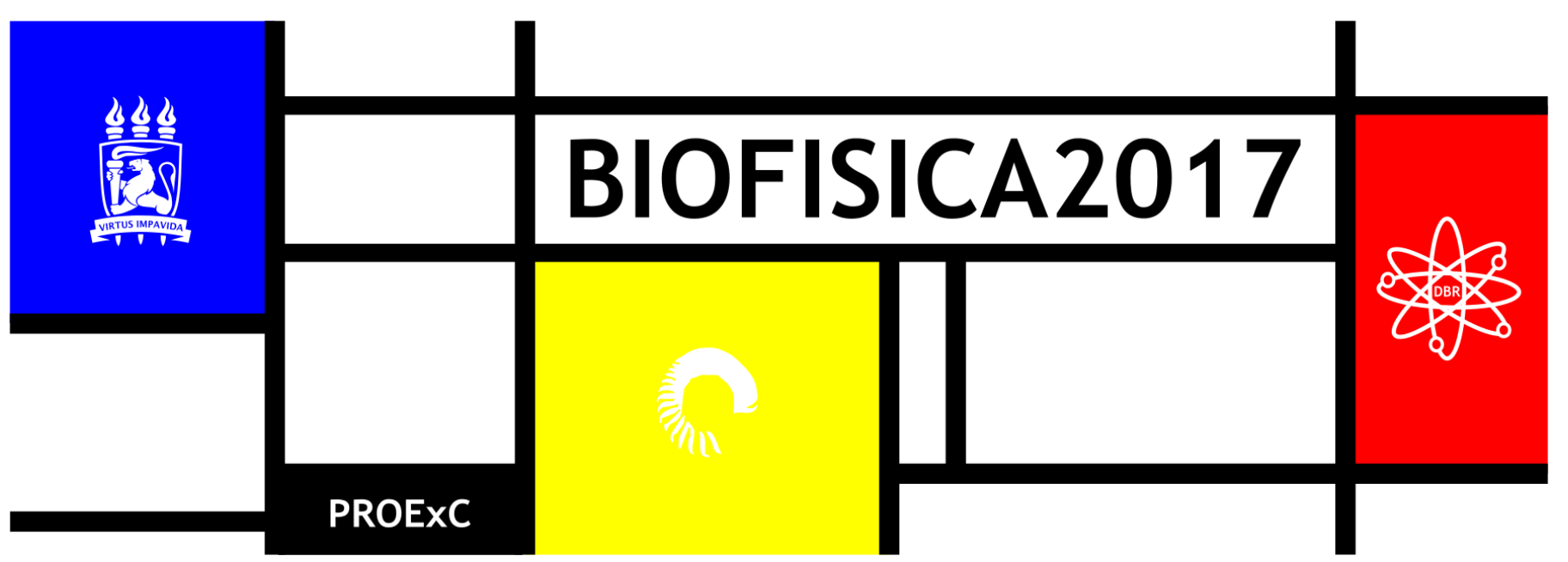

\title{
OTIMIZAÇÃO DE VEÍCULO FARMACÊUTICO TÓPICO CONTENDO AZUL DE METILE- NO PARA USO EM TERAPIA FOTODINÂMICA
}

\author{
Lucas A. G. da Costa ${ }^{1 *}$, Juliana S. A. Falcão ${ }^{1}$, Luíza B. M. Santos ${ }^{1}$, Adriana Fontes², Beate S. Santos ${ }^{1}$ \\ ${ }^{1}$ Departamento de Ciências Farmacêuticas, UFPE \\ ${ }^{2}$ Departamento de Biofísica e Radiobiologia, UFPE \\ *lucas.amadeu@ufpe.br
}

\section{INTRODUÇÃO}

A terapia fotodinâmica (TDF) é definida como uma terapia que utiliza reações fotoquímicas para destruição seletiva de tecido ou células. É uma técnica terapêutica de dois estágios no qual o uso de uma droga sensibilizadora tópica ou sistêmica é seguido pela irradiação de luz visível. Os fotossensibilizadores, administrados de forma exógena ou formados endogenamente, são ativados pela luz e transferem sua energia para o oxigênio molecular, gerando espécies reativas de oxigênio (ROS) que induzem morte celular, como esquematizado na Figura 1.

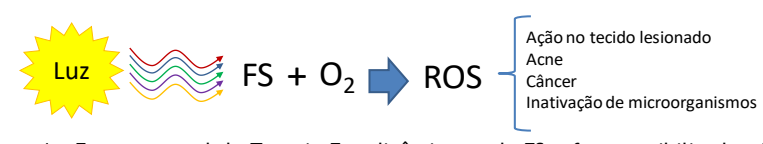

Figura 1 - Esquema geral da Terapia Fotodinâmica, onde FS = fotossensibilizador, ROS = espécie reativa de oxigênio.

A Figura 2 apresenta um esquema geral que ilustra os diferentes processos que ocorrem a partir da excitação de um fotossensibilizador por uma fonte de luz. A absorção de um fóton de luz promove a excitação e transição do FS do estado fundamental para o estado excitado singleto. Neste estado, o FS pode regressar ao estado fundamental por emissão de fluorescência ou passar ao estado excitado tripleto onde pode reagir com o oxigênio molecular de duas formas distintas (reação tipo I e reação tipo II). Na reação do tipo I, o FS reage diretamente com o substrato, membrana celular ou uma molécula, essa reação permite a transferência de elétrons ( $\left.e^{-}\right)$formando íns ou radicais derivados do FS e do substrato. As espécies reativas são formadas por reducões de um ou mais elétrons no oxigênio $\left(\mathrm{O}_{2}\right)$. Os produtos desta redução incluem ânion superóxido $\left(\mathrm{O}_{2}{ }^{-}\right)$, peróxido de hidrogênio $\left(\mathrm{H}_{2} \mathrm{O}_{2}\right)$, radical alcoxila, radical peroxila e radical hidroxila $\left(\mathrm{OH}^{-}\right)$.

Os FS podem ser administrados por várias vias, sendo a via tópica uma alternativa para o tratamento de micoses, cânceres de pele, infestações parasitárias ou infecções bacterianas. Apesar de ter um campo de ação visível, tal via também apresenta uma grande complexidade para a ação fototerápica, tais como: as características ópticas do tecido, os processos de reflexão, absorção, espalhamento de luz e o estado funcional do tecido. Como exemplo, a pele escura absorve mais luz no visível em comparação à pele clara devido a maior quantidade de melanina, um dos principais cromóforos do tecido biológico. No caso de lesões, a penetração da luz é maior se comparada à pele normal de espessura similar. Para isso, é necessário o desenvolvimento de formulações farmacêuticas capazes de veicular os FS ao local acometido pela lesão tecidual, levando em consideração as propriedades ópticas do tecido-alvo.

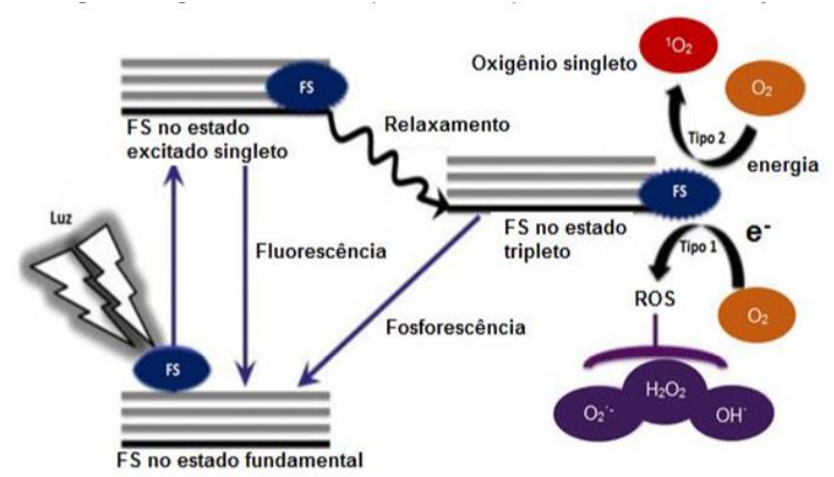

Figura 2 - Esquema ilustrando os possiveis processos durante a terapia fotodinâmica com o processo de excitação do FS e formação de ROS. [Fonte: Adaptado de TEGOS et al (2012); COSTA (2013); VIANA (2015)].

Neste sentido, este trabalho visa o desenvolvimento de uma formulação simples na forma gel para incorporação de fotossensibilizadores com a finalidade de aplicação em terapia fotodinâmica. Os géis são sistemas semissólidos nos quais o movimento do meio dispersante é restrito por uma rede tridimensional de partículas interlaçadas ou macromoléculas solvatadas presentes na fase dispersa. Pode estar envolvido um alto grau de interações físicas ou químicas. 0 aumento da viscosidade causado pelo entrelaçamento e consequente atrito interno é responsável pelo estado semissólido. Um gel pode consistir de filamentos torcidos e emaranhados que geralmente se mantêm unidos por ligações do tipo Van der Waals, formando regiões cristalinas e amorfas ao longo do sistema.

O azul de metileno (AM) é um corante catiônico e que por ser relativamente lipofílico, capaz de permear membranas e por possuir carga positiva é atraído pelo potencial negativo das mitocôndrias, podendo atuar nesta organela. Este FS é atualmente empregado no tratamento de infecções bucais, periodontite e descontaminação endodôntica. Ele possui ainda, boa eficácia de geração de ${ }^{1} \mathrm{O}_{2}$, em torno de $50 \%$. Sua estrutura molecular está representada na Figura 3. A Figura 3 mostra a aplicação de azul de metileno (em solução aquosa) no tratamento de periodontite. 


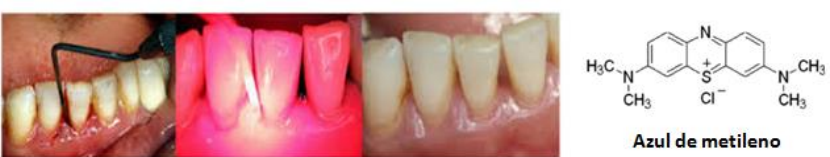

Figura 3 - Aplicação de terapia fotodinâmica no tratamento de periodontite utilizando-se o fotossensibilizador azul de metileno em solução aquosa e fonte de luz vermelha. (Fonte: www.researchgate.net/figure/223961765_fig1_Patient-with chronic-periodontitisbefore-treatment-left-during-photodynamic-therapy).

\section{MATERIAIS E MÉTODOS}

Formulações a base de gel carbopol $940 \AA$ (Figura 4) foram preparadas contendo FS na concentração $5 \times 10^{-6} \mathrm{~mol}^{-L^{-1}}$ (SANTOS, 2016).

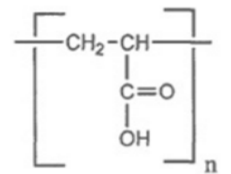

Figura 4 - Monômero do Carbopol 940.

A detecção de ROS do FS foi então avaliada antes e após incorporação ao gel, através do método químico indireto empregando-se agentes químicos N,N-dimetil-4-nitrosoanilina (RNO) e Lhistidina (KRAJLIC \& MOHSNI, 1978). 0 método consiste da análise do padrão de degradação do RNO a partir do intermediário altamente reativo gerado pelo ataque do ROS a L-histidina. A produção de ROS equivale à queda na densidade óptica do RNO, dessa forma a quantificação de ROS foi avaliada a partir do coeficiente angular da reta, e percentual de produção de ROS calculado a partir das Equações:

$$
R N O c=\frac{A B S_{\mathrm{f}} \times 100}{A B S_{\mathrm{i}}} \quad R O S p=100-R N O C
$$

Onde:

$R N O c=$ percentual de RNO consumido

$A B S_{i}=$ absorbância inicial do fotossensibilizador

$A B S_{f}=$ absorbância final do fotossensibilizador

$R O S p=$ percentual de produção de ROS

A geração de ROS foi induzida irradiando-se com laser $(660 \mathrm{~nm})$ as formulações contendo AM (solução e gel), durante o período de 0 a 5 minutos, sendo a análise feita a cada $20 \mathrm{~s}$ ou a cada 1 min. Espectros de absorção eletrônica foram registrados entre 350 e $450 \mathrm{~nm}$ (espectrofotômetro modelo Lambda 650 UV/Vis, Perkin Elmer da Central Analítica do Depto. Química Fundamental, UFPE). A determinação da espalhabilidade foi realizada de acordo com metodologia descrita por Zanin et al. (2001).

\section{RESULTADOS E DISCUSSÃO}

Os resultados de varredura completa dos espectros dos componentes do estudo de detecção de ROS (de 200 a $900 \mathrm{~nm}$ ) confirmaram que não houve interferência na análise do resultado da leitura do RNO, conforme visto na Figura 5.

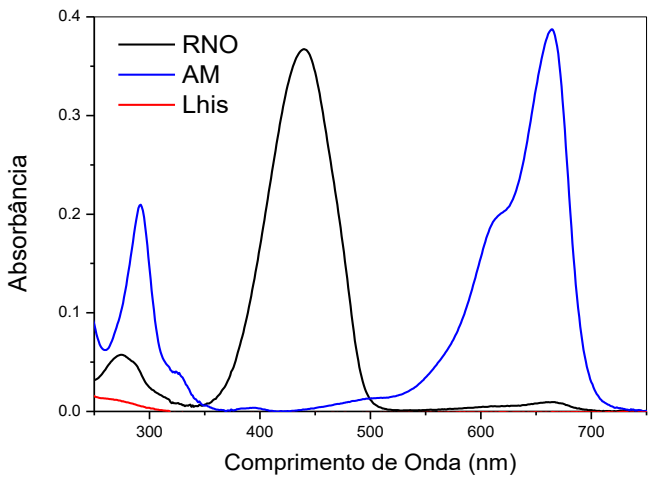

Figura 5 - Espectros de absorção dos componentes do método de ROS. Não há interferência entre os componentes (RNO, L-histidina e AM).
Os primeiros resultados foram obtidos em solução, pleiteando que o ROS foi gerado e que o RNO captou tal geração a partir de sua degradação (Figura 6). A degradação foi feita, inicialmente, com o intervalo de $20 \mathrm{~s}$ entre cada leitura, até totalizar 5 min. Ocorreu uma queda na taxa de degradação ao longo do tempo. É interessante reparar na existência de um ponto isosbéstico ( $\lambda$ $=380 \mathrm{~nm}$ ), ponto onde a absorção de duas ou mais espécies é a mesma, o que sugere a existência de um produto de degradação do RNO com absorção próxima.

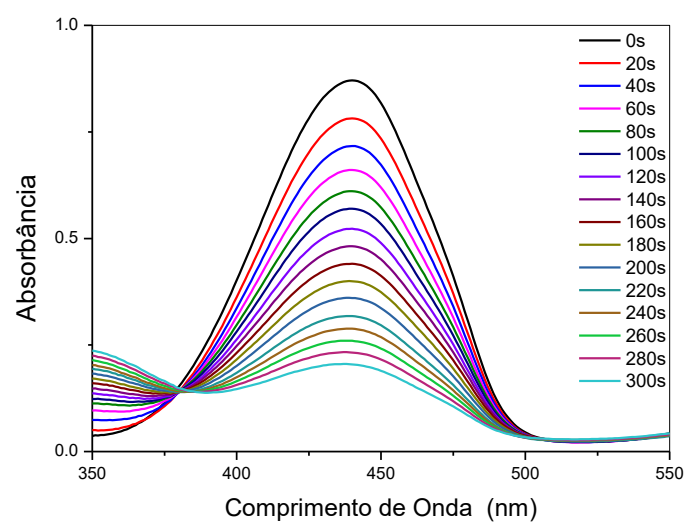

Figura 6 - Curvas de degradação do RNO ao longo dos 5 min de irradiação $(\lambda=660 \mathrm{~nm})$ com um intervalo de 20 s entre cada irradiação da solução contendo AM $\left(5 \mu \mathrm{mol} . \mathrm{L}^{-1}\right)$.

O principal resultado obtido a partir dessa análise foi que o intervalo de irradiação da amostra interfere na geração de ROS, como visto na Figura 7: se o intervalo de exposição for de $1 \mathrm{~min}$, a taxa de degradação é menor $(65 \%)$ do que se for com intervalos de $20 \mathrm{~s}(75 \%)$. Isto decorre provavelmente de variações de concentração das espécies reativas de oxigênio formadas durante a irradiação do $A M$ e a presença de $\mathrm{O}_{2}$ no meio. $\mathrm{O}$ fato do sistema ser homogeneizado a cada $20 \mathrm{~s}$ pode estar favorecendo o processo, através do maior contato da solução com o ar.

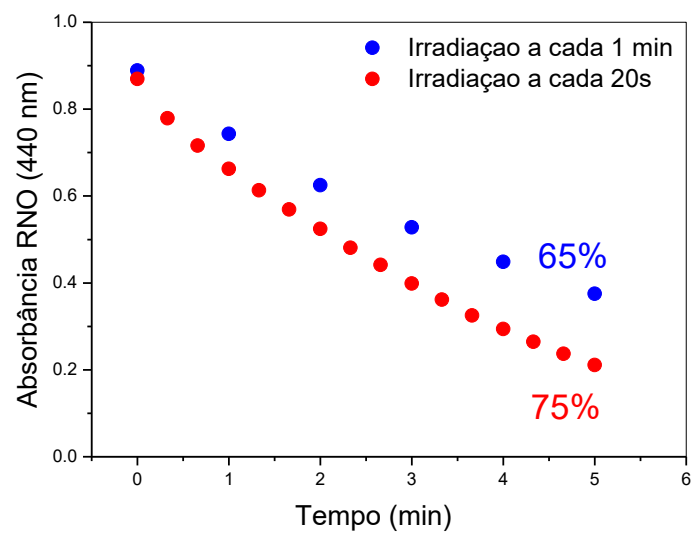

Figura 7 - Curvas com o valor da absorbância em $440 \mathrm{~nm}$ indicando a degradação do RNO em duas situações de irradiação do laser $(\lambda=660 \mathrm{~nm})$ : a cada $1 \mathrm{~min}(\bullet)$ e a cada $20 \mathrm{~s}(\bullet)$

Após a preparação dos géis observou-se que não houve alteração macroscópica significativa na forma semissólida após sua incorporação. Os géis (placebo, gel/AM) demonstraram pH em torno de 6,0 , viscosidade $2 \times 10^{6} \mathrm{CP}$ e espalhabilidade máxima de 4032-4808 $\mathrm{mm}^{2}$ nas condições de estudo confirmando que a baixa concentração não modificou as propriedades gerais do gel.

No entanto, foi observado que a resposta da produção de ROS do AM é reduzida em torno de $25 \%$ após sua incorporação no gel, quando comparada à produção em solução aquosa. As hipóteses para o decaimento da geração de ROS do AM na formulação em gel podem estar atribuídas às interações intermoleculares ou a auto supressão de fluorescência. A molécula de azul de metileno com 
carga levemente positiva (Figura 3 ) tem possibilidade de interagir com a malha polimérica do gel carbopol (poliânion). Esta interação supramolecular pode levar à uma mobilidade menor das moléculas deste FS, reduzindo a seção de choque com o oxigênio livre dissolvido no meio aquoso. Outra possibilidade é no gel, as moléculas podem sofrer um adensamento local das espécies de AM. Ou seja, uma concentração de espécies de $A M$ pode causar um efeito conhecido como autos supressão durante sua irradiação com luz. Isto fica ainda mais complexo quando se observa o espectro de absorção e o de emissão do AM onde se evidencia um pequeno deslocamento de Stokes e uma região espectral de grande superposição da banda de absorção e a de emissão. Assim, ao emitir luz quando irradiado pode ocorrer a absorção desta luz pelo próprio $A M$, reduzindo sua eficiência para geração de ROS. Estas possibilidades serão testadas realizando-se estudos da dependência da concentração da espécie na formulação semissólida com a eficiência de produção de ROS.

\section{CONCLUSÕES}

A partir dos resultados pode-se concluir que a incorporação do FS não alterou de modo microscópico as características do gel, bem como seu pH. Nos testes prévios realizados em solução observou-se que uma exposição mais prolongada da fonte de luz diminui a taxa de geração de ROS, o que sugere que o tempo entre uma exposição e outra é fundamental na cinética da reação. É esperado que a taxa de geração de ROS seja alterada pela presença do gel, já que a mobilidade das moléculas do ativo, bem como a penetração de luz mude o padrão observado.

\section{REFERÊNCIAS}

COSTA, L. D. S. Síntese e Caracterização de Porfirinas como Potenciais Agentes Fotossensibilizadores em Terapia Fotodinâmica. Dissertação - Mestrado, Departamento de Ciências da Vida, Universidade de Coimbra, Coimbra, 2013.

SANTOS, L.B.M., Incorporação de Zincoporfirina e Azul de Metileno em Gel e Avaliação Para Uso em Terapia Fotodinâmica. Dissertação de Mestrado, Ciências Farmacêuticas, UFPE, 2016.

KRALJIC, I, MOHSNI, S. E. A New Method for the Detection of Singlet Oxygen in Aqueous Solutions. Photochem. Photobiol. 28, 577581, 1978.

TEGOS, G., et al. Concepts and principles of photodynamic therapy as an alternative antifungal discovery platform. Frontiers in Microbiology 3, 120, 2012.

VIANA, O. S. Desenvolvimento de sistemas nanoestruturados à base de quantum dots livres e associados à porfirinas para aplicação em sistemas biológicos. Centro de Ciências da Saúde, Universidade Federal do Pernambuco, Recife, 2015.

ZANIN, S. M. W. et al. Parâmetros físicos no estudo da estabilidade das emulsões. Revista Visão Acadêmica, Curitiba, 2, p. 47-58, 2001. 